\title{
Caregiving profiles of mothers in an economically disadvantaged sample from Turkey: An observational study
}

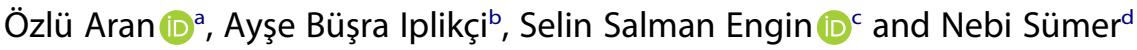

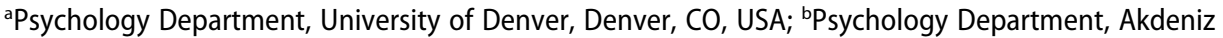 \\ University, Antalya, Turkey; 'Psychology Department, Bilkent University, Ankara, Turkey; ${ }^{\text {dFaculty }}$ of Arts and \\ Social Sciences, Sabanci University, Istanbul, Turkey
}

\begin{abstract}
Objective: This study aims to investigate the patterns of maternal sensitivity via structured and systematic observational methods among mothers from a disadvantaged community in Turkey. Background: Caregiving sensitivity is shaped by cultural parenting ethnotheories, and there is a need to examine in non-Western cultures to see its universal and culturally-specific features.

Method: Ninety-eight mothers and their interactions with infants were videotaped during home-visits, and their caregiving behaviours were assessed via the Maternal Behaviour Q-Set.

Results: Results of the Q-factor analysis revealed two distinct caregiving profiles. The first profile, 'sensitivity vs. insensitivity', describes mothers who were characterised by sensitive behaviours to their babies, and acceptance of their infant. Mothers in this group were more aware and responsive to their babies' needs and demands. The second profile, 'nonsynchronous vs. synchronous', describes mothers who showed noncontingent behaviours during interactions such as being unable to follow the pace of the infant or to respond to infants' needs on time.

Conclusion: This study contributes to the literature by showing that mothers from Turkey can be grouped in terms of sensitivity similar to the previous studies, although the descriptive behaviours of sensitivity may vary.
\end{abstract}

\section{ARTICLE HISTORY}

Received 31 August 2019

Accepted 21 January 2020

\section{KEYWORDS}

Maternal caregiving behaviours; maternal sensitivity; q-factor analysis; naturalistic observation; low SES

Maternal sensitivity is a key factor determining the quality of early interactions between mothers and infants, and this interaction is highly important for healthy development of children (Ainsworth, Blehar, Waters, \& Wall, 1978; Bornstein \& Tamis-LeMonda, 1989; Bowlby, 1983; Landry, Smith, \& Swank, 2006; Posada et al., 2016). Past research shows universality in fundamental characteristics of maternal sensitivity across cultures (Ainsworth et al., 1978; Mesman et al., 2016; Posada, Carbonell, Alzate, \& Plata, 2004). As emphasised by Ainsworth et al. (1978), there is a need to examine maternal sensitivity cross-culturally to identify its universal and culturally specific features (Broesch, Rochat, Olah, Broesch, \& Henrich, 2016; Mesman et al., 2016). The current study aims to empirically describe the patterns of maternal behaviours by grouping mothers based on the pattern of sensitive caregiving behaviours in 
the Turkish cultural context, where a substantial number of mother-infant dyads lives in economically disadvantaged conditions.

\section{Maternal sensitivity across cultures}

Maternal sensitivity is broadly defined as a mother's attentiveness to infant signals and correct interpretation of those signals, which in turn, is expected to lead to prompt and appropriate responses (Ainsworth, Bell, \& Stayton, 1971; Posada et al., 2016). Ainsworth, Bell, and Stayton (1974) suggest four domains of sensitivity: sensitive responding to the infant's signals and communications, accessibility, acceptance of the infant, and cooperation with the infant's behaviour. The last three domains show .80 correlation with sensitive responding to the infant's signals and communications domain, so it is alone widely used as a global measure of sensitivity (Ainsworth et al., 1978). It is also a dimension that is universally recognised (van ljzendoorn \& Sagi, 1999) and shows convergence with maternal reports of the ideal caregiving behaviours across cultures (Mesman et al., 2016). However, a considerable amount of research on maternal sensitivity comes from Western cultures. The domain of maternal sensitivity has been defined and constructed mostly from the data of American and European societies (Rothbaum, Weisz, Pott, Miyake, \& Morelli, 2000; Sümer, Sayıl, \& Kazak-Berument, 2016).

When cultural differences are taken into account, studies mostly demonstrated differences in behavioural level rather than domain level (Rogoff, 2003; Rothbaum, Nagaoka, \& Ponte, 2006). For example, while mothers' responses to infant signals show very similar patterns in Fiji and the USA, their response preference to the type of signal may change. That is, mothers in the US respond more to positive signals, whereas, mothers in Fiji respond more to negative signals (Broesch et al., 2016). Moreover, in Japan mothers show higher physical proximity to their children compared to mothers in the USA because culturally mothers are expected to respond to infant needs proactively, while in the USA mothers are expected to wait for infant signals to respond in a reactive manner (Rothbaum et al., 2000). Those differences in behavioural level are thought to exist along with the universal domain of global sensitivity (van ljzendoorn \& Sagi-Schwartz, 2008). In one study, Posada et al. (2004) focused on sensitivity domains across cultures. By using the ethnographic methodology in a Colombian sample, they obtained caregiving domains in addition to the four fundamental domains such as consistency of response, or frequency and diversity of functions in maternal verbal communication. While these domains correspond to much of Ainsworth's conceptualisation for the quality of early care, they also signal the existence of culturally specific domains beyond the behavioural level. Likewise, a previous study found that when investigated independently from Western standards, caregiving in Turkey can show different behavioural patterns (Aran, Iplikci, Selcuk, \& Gunaydin, in press). In that study, a low-risk sample of mothers from Turkey was observed at home. Their maternal sensitivity scores; however, were not compared to Western-based maternal sensitivity criteria. Instead, each individual was treated as a variable and naturally occurring differences in behavioural patterns were investigated to see whether behaviour clusters created any dimensions. The sample with a relatively high level of sensitivity revealed two caregiving clusters instead of one global dimension of sensitivity. Although the first group resembled the universal characteristics of maternal sensitivity, there was a second dimension specifically describing mothers who were indifferent to the needs of their infants and responded only if the infants persistently 
demanded attention. In light of these recent findings, both universal and culturally specific features of maternal sensitivity found support in the literature. However, as demonstrated by Mesman et al. (2016), differences in maternal sensitivity mostly stem from socioeconomic varibility. Therefore, we primarily aim to examine the pattern of maternal sensitivity among economically disadvantaged mothers in Turkey.

\section{Maternal sensitivity in low SES context}

A considerable amount of work evidenced that quality of parental care is negatively affected by disadvantaged environmental conditions and lower socioeconomic status (SES) is considered a risk factor for the healthy development of children (Choe, Olson, \& Sameroff, 2013; Roubinov \& Boyce, 2017; Sameroff, 1998, 2000). Parents experiencing economic hardship have difficulty providing a safe, predictable, and stimulating environment to their children. They also exhibit less sensitivity when they interact with their children. A combination of those factors can have adverse psychological and social influences in development (Aber, Jones, \& Cohen, 2000; Bradley \& Corwyn, 2008; Lemelin et al., 2007; Seow, 2012). Mothers in low SES families are observed to be engaging in less synchronic and responsive behaviours in their interactions with their children (Aviezer, Sagi-Schwartz, \& Koren-Karie, 2003; Evans, Heron, Lewis, Araya, \& Wolke, 2005; Shin, Park, \& Kim, 2006; Tamis-LeMonda, Bornstein, \& Baumwell, 2001; Tarabulsy et al., 2005). Moreover, low SES is related to more instability within the family and higher levels of harsh parenting (Fiese, Rhodes, \& Beardslee, 2013; Heron, O'Connor, Evans, Golding, \& Glover, 2004; McLoyd \& Wilson, 1991). Therefore, revealing caregiving patterns in low-risk populations can inform prevention and intervention programmes.

As a developing country, approximately $27 \%$ of the population in Turkey live under the poverty threshold (TURKSTAT, 2017). Given this statistic and the uniqueness of the cultural context which embraces a blend of Western and Eastern values (Inalcık, 1998), it is highly likely that mothers with low SES backgrounds in Turkey might differ from high SES mothers and their Western counterparts with respect to maternal behavioural patterns. Indeed, family dynamics in Turkey are different from both typical Western and Eastern family types (Kağıtçıbaşı, 2005; Kağıtçıbaşı \& Ataca, 2005). Therefore, we aim to address the gap by investigating maternal caregiving behaviour profiles in a financially disadvantaged sample in the unique cultural context of Turkey.

\section{Current study}

Maternal sensitivity has both universal and unique features across cultures. So far, those differences are mostly demonstrated on the behavioural level (Rogoff, 2003), but domain level differences are also suggested (Posada et al., 2004). Moreover, low SES is a risk factor for maternal sensitivity (Simona et al., 2014). Besides, there are only limited data about maternal sensitivity from countries where the main religion is Islam (van ljzendoorn \& Sagi, 1999). As one previous study showed, caregiving is represented by two different behavioural patterns in Turkey (Aran et al., in press). However, this has not been tested in a socioeconomically disadvantaged sample yet. Therefore, the present report aims to explore the patterns of caregiving behaviours in mothers coming from a risk sample in Turkey by using observation methodology. It is expected that a vast majority of mothers would fall into the sensitive 
mother profile. Beyond this profile, it is anticipated that there would be one more profile in line with previous findings in Turkey. Moreover, the behavioural content of the second profile is an explanatory feature of the current study. We do not have a specific hypothesis for the behavioural features of our expected second caregiving profile.

\section{Method}

\section{Participants}

We contacted community centres and local authorities in low SES regions of the two largest cities in Turkey. Participants were selected from mothers who had infants with an age range of 9-36 months. Mothers from disadvantaged neighbourhoods and with high school or lower degrees were the target of the study. Among 132 mother-infant dyads who agreed to participate in the study, 98 provided natural observation data (see Figure 1). This sample size is consistent with previous studies examining maternal sensitivity profiles (e.g. Aran et al., in press; Bailey, Moran, Pederson, \& Bento, 2007). The mean ages of mothers and infants and the gender distribution of infants can be seen in Table 1. Fifty-one of infants

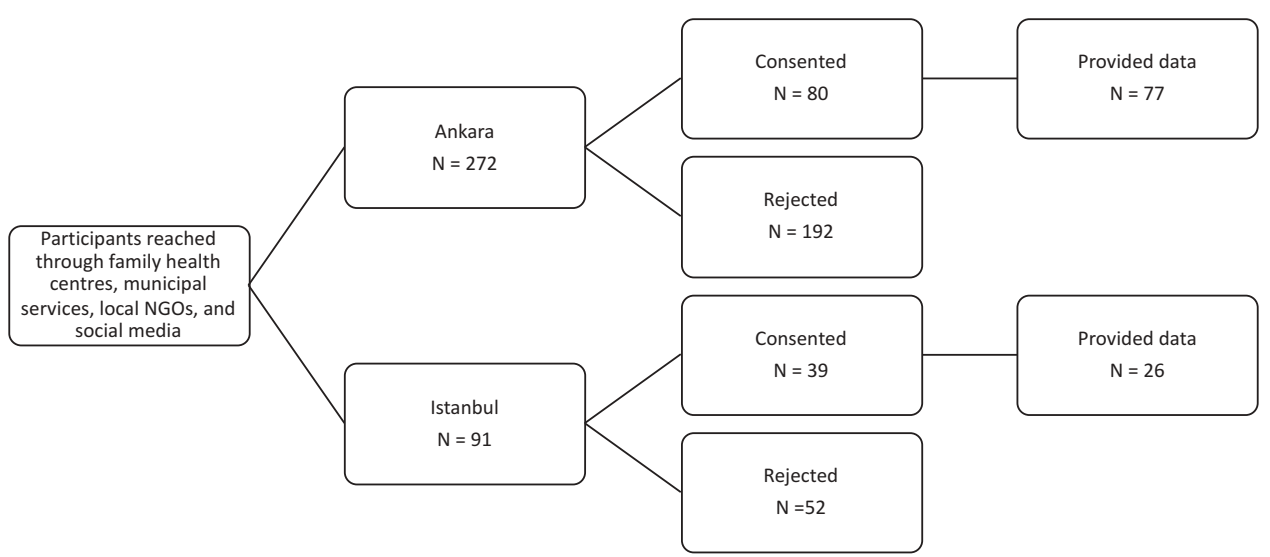

Figure 1. Participant flow.

Table 1. Demographic characteristics of the study sample.

\begin{tabular}{|c|c|c|c|c|c|c|}
\hline & \multicolumn{3}{|c|}{ Mothers } & \multicolumn{3}{|c|}{ Infants } \\
\hline & M & SD & $\%$ & $M$ & SD & $\%$ \\
\hline Age & 29.61 years & 5.18 & & 19.63 months & 6.39 & \\
\hline \multicolumn{7}{|l|}{ Gender } \\
\hline Female & & & & & & 48.54 \\
\hline Male & & & & & & 51.46 \\
\hline \multicolumn{7}{|l|}{ Education Level } \\
\hline Primary school & & & 13.74 & & & \\
\hline Secondary school & & & 22.33 & & & \\
\hline High school & & & 48.54 & & & \\
\hline University & & & 13.74 & & & \\
\hline \multicolumn{7}{|l|}{ Job situation } \\
\hline Homemaker & & & 80.58 & & & \\
\hline Unemployed & & & 5.83 & & & \\
\hline Part-time & & & 3.88 & & & \\
\hline Full-time & & & 7.78 & & & \\
\hline
\end{tabular}


were the first child (49.51\%), 44 of them were second $(42.72 \%)$, and the rest was the third or fourth child (6.87\%). All dyads were living in Ankara $(n=77)$ or Istanbul $(n=26)$ at the time of data collection.

Parallel to the target of the study sample, the majority of mothers was not working (see Table 1). Family income was asked on a five-point scale with the lowest amount is under 1000 Turkish Liras, and the highest is 5000 Turkish Liras and above. Ninety-eight per cent ( $n=96$ ) of the mothers reported that their income was under the poverty threshold reported in 2015 (TURKSTAT, 2015). The poverty threshold, which was 4.394,87 Turkish Liras, is determined by considering expenses of basic needs of a family such as food, clothes, bills, rent, transportation, education, and health.

\section{Materials}

Maternal sensitivity was measured by using the Turkish adaptation of the Maternal Behaviour Q-Set (MBQS; Pederson \& Moran, 1995; Selçuk et al., 2010; Sümer et al., 2016). The MBQS is a commonly used measure of caregiving behaviours. It offers the identification and analyses of complex patterning of maternal behaviours. It consists of 90 statements that describe maternal behaviours, and observers sort those statements into nine piles with respect to the frequency of behaviours performed by mothers (i.e. 'Responds accurately to signals of distress', 'Displays affection by touching, caressing.'). The first three piles refer to the least describing behaviours, the middle three piles refer to either unobserved or less describing behaviours, and the last three piles refer to most describing behaviours of mothers. To determine mothers' sensitivity, mothers' scores were compared to the sensitivity criteria which is rated by experts in caregiving to determine ideal caregiver behaviours (Pederson et al., 1990). In the current study, rather than using these criteria, naturally occurring variations in caregiving behaviours of the mothers in the sample were taken into account. Researchers coded MBQS via using METU Q-soft software (Sümer et al., 2016), which is developed to sort MBQS items. In total, $18 \%$ of the videos were double coded, and the inter-coder reliability scores ranged from .74 to .92 .

\section{Procedure}

This study was the part of a larger intervention project funded by the Scientific and Technological Research Council of Turkey (TUBITAK). After the ethical approval was obtained from the Middle East TechnicalUniversity Ethics Committee, mother-infant dyads were recruited via convenience sampling. In the current study, only the pre-test data of the intervention project is used to describe caregiving profiles. During the visit, mothers were asked to maintain their daily routine with children, and the researchers recorded for an hour without intervening. In addition, mothers and infants were provided with two different toys and recorded for ten minutes during free play totalling 70 minutes of recording. The MBQS ratings were done by trained coders blind to the conditions of the study.

\section{Data analyses}

Q-factor analyses were conducted by using 'qmethod' package for R Software, designed for the factor analysis of q-sort data (Zabala, 2014). This method allows researchers to factor 
Table 3. Items describing the nonsynchronous vs. synchronous profile.

\begin{tabular}{|c|c|}
\hline Most Describing Items (9) & Least Describing Items (1) \\
\hline $\begin{array}{l}\text { 17. Content and pace of interaction set by mother } \\
\text { rather than according to baby's responses. }\end{array}$ & $\begin{array}{l}\text { 34. Interactions revolve around baby's tempo and current } \\
\text { state. }\end{array}$ \\
\hline 85. Interactions with baby are incomplete. & $\begin{array}{l}\text { 53. Slows pace down, waits for baby's response during } \\
\text { interactions. }\end{array}$ \\
\hline 23. Provides baby with unrestricted access to her. & $\begin{array}{l}\text { 19. Places baby in another room when baby is in a bad mood } \\
\text { or cranky. }\end{array}$ \\
\hline $\begin{array}{l}\text { 16. During ongoing interactions, misses slow down or } \\
\text { back off signals from baby. }\end{array}$ & $\begin{array}{l}\text { 35. Well resolved interaction with baby - interaction ends } \\
\text { when baby is satisfied. }\end{array}$ \\
\hline $\begin{array}{l}\text { 69. Notices when baby is distressed (e.g. cries, fusses or } \\
\text { whimpers). }\end{array}$ & $\begin{array}{l}\text { 33. Repeated series of interventions in search of best method } \\
\text { to satisfy baby, resorts to trial and error. }\end{array}$ \\
\hline 52. Uses verbal prohibitions (e.g. 'no or don't') & 71. Builds on the focus of baby's attention. \\
\hline
\end{tabular}

Table 2. Items describing the sensitivity vs. insensitivity profile.

\begin{tabular}{|c|c|}
\hline Most Describing Items (9) & Least Describing Items (1) \\
\hline 65. Responds to baby's signals. & $\begin{array}{l}\text { 5. Awkward and ill at ease during intimate interactions } \\
\text { with baby. }\end{array}$ \\
\hline 10. Speaks to baby directly. & 66. Consistently unresponsive. \\
\hline 51. Provides age appropriate toys. & 88. Interactions with baby are characterised by conflict. \\
\hline $\begin{array}{l}\text { 48. Points to and identifies interesting things in baby's } \\
\text { environment. }\end{array}$ & 3. Mother's responses are unpredictable. \\
\hline 57. Shows delight in interaction with baby. & 90. Punitive or retaliatory during interactions with baby. \\
\hline 81. Spontaneously expresses positive feelings to baby. & 87. Actively opposes baby's wishes. \\
\hline
\end{tabular}

analyse participants, mothers in our case, rather than items. By using this method, mothers showing similar behaviour patterns are grouped together. Thus, mothers were treated as variables, and the MBQS items were considered as cases. After q-factor analysis, the number of factors was selected according to eigenvalues and the scree plot criterion (Cattell, 1966). In the factor description part, the q-factor analysis calculates a distribution of 90 items by using the factor loadings of items for each factor as the best fit. This distribution was used to identify the most and least describing items for each factor (see Tables 2 \& 3). According to these distributions, ten items with the highest loadings were named as most describing items and ten items with the lowest factor loadings were named as least describing items of that factor. By using these factor loadings, most and least describing behaviours of mothers were determined; and those behaviour patterns were used to name each factor. Moreover, all items were labelled as either distinguishing or consensus items where distinguishing items referred to the items explaining that factor and consensus items referred to the items that did not explain any difference between factors. The behaviour patterns of mothers were named and described according to the most and the least loaded distinguishing items for that factor.

\section{Results}

Principal Component Analysis with Varimax rotation was performed for the MBQS ratings of mothers in order to group mothers according to their common behaviour patterns. Because there were two possible factors with eigenvalues greater than one, an analysis with two-factor-solution was performed. With this solution, $49.62 \%$ of variance accounted for Factor 1 and $14.39 \%$ for Factor 2 . The two factors were strongly correlated $(r=.58, p$ 
$<.001)$. The correlation of factors with the MBQS criterion sort was .86 for first factor and .32 for the second factor.

Mothers were organised and specified in terms of the two factors. Specifically, the majority of mothers ( $n=77,78.57 \%$ ) loaded on the first factor. Depending on the most and the least descriptive items, this factor was labelled as 'sensitivity vs insensitivity' (see Table 2). Mothers who had high positive loadings on the first factor were characterised by sensitive behaviours to their children, and acceptance of them. They were more aware and responsive to their children's needs and demands. They followed the pace of their children and tended to adapt their behaviours according to them. They were more likely to cooperate with their children, and they usually payed attention child mood. Their interaction continued in a positive and responsive environment. The behaviours of mothers with high negative loadings were characterised by relative unresponsiveness to their children. Mothers in this group were characterised as failing to understand the needs of their children. They were likely to have limited interaction, and most of the time, they were busy with their own activities (see Table 2).

For the second factor, 'nonsynchronous vs. synchronous', 21 mothers (21.43\%) significantly loaded on the second factor representing items related to mothers' synchrony with children (see Table 3). Mothers who had positive loadings displayed nonsynchronous behaviours during interactions such as being unable to follow the pace of the infant or to response their needs on time. These mothers were not tolerant of non-cooperation in general, and they tried to impose their own agendas rather than paying attention to children's demands. They usually missed the signals for interaction. During interaction, they tended to cut the interaction without considering child satisfaction. On the other side of this factor, some mothers responded to infants' needs on time and adapted their pace according to that of infants.

Finally, to eliminate possible confounding effects of age of mother and children, and children's gender, t-tests for mothers' age, children's age, and a chi-square test for children's gender and mothers' employment were conducted. There was no significant difference between the groups for any of these variables (See Table 4).

Table 4. Comparison of demographic variables between two caregiving profiles.

\begin{tabular}{|c|c|c|c|}
\hline & Profile 1 & Profile 2 & \multirow[b]{2}{*}{ Significance } \\
\hline & $(n=77)$ & $(n=21)$ & \\
\hline Age - Mother (years) Mean (SD) & $29.35(4.99)_{\mathrm{a}}$ & $30.60(5.89)_{\mathrm{a}}$ & $t(94)=-.96, p=.34$ \\
\hline Age - Child (months) Mean (SD) & $19.78(6.73)_{\mathrm{a}}$ & $17.90(5.90)_{a}$ & $t(96)=1.25, p=.22$ \\
\hline Completed Education Level & & & $X^{2}(5, N=96)=10.16, p=.07$ \\
\hline Primary School & $7(9.1 \%)_{a}$ & $6(30 \%)_{a}$ & \\
\hline Secondary School & $17(22.1 \%)_{a}$ & $6(30 \%)_{a}$ & \\
\hline High School & $41(53.2 \%)_{a}$ & $7(35 \%)_{a}$ & \\
\hline College & $12(15.62 \%)_{a}$ & $1(5 \%)_{a}$ & \\
\hline Employment Status & $\mathrm{n}(\%)$ & $\mathrm{n}(\%)$ & $X^{2}(3, N=96)=1.17, p=.76$ \\
\hline Homemaker & $62(81.6 \%)$ a & $18(90 \%)_{a}$ & \\
\hline Nonworking & $5(6.6 \%)$ a & $1(5 \%)_{a}$ & \\
\hline Part-time & $6(7.9 \%)_{a}$ & $1(5 \%)_{a}$ & \\
\hline Full-time & $3(3.9 \%)_{a}$ & $0(0 \%)_{a}$ & \\
\hline Child Gender & & & $X^{2}(1, N=98)=.01, p=.94$ \\
\hline Female & $36(46.8 \%)_{a}$ & $10(47.6 \%)_{a}$ & \\
\hline Male & $41(53.2 \%)_{a}$ & $11(52.4 \%)_{\mathrm{a}}$ & \\
\hline
\end{tabular}




\section{Discussion}

This study has extended the findings examining maternal sensitivity in different cultural and SES contexts with natural observations at home. Overall, the results of q-factor analyses showed that there are two major profiles of mothers' caregiving behaviours in an economically disadvantaged sample in Turkey. Majority of the mothers in this sample had high scores in the 'sensitivity' category similar to Ainsworth's et al. (1978) theoretically derived 'sensitivity-insensitivity' factor. The items describing this group signify the importance of prompt responsiveness, showing delight and positive feelings, and structuring a secure environment. This profile was also similar to the previous studies using q-sort methodology (e.g. Bailey et al., 2007; Bailey, Waters, Pederson, \& Moran, 1999; Mesman et al., 2016), although the descriptive behaviours of sensitivity varied. Mothers' scores in that group were highly correlated with the standard MBQS criterion supporting the validity of the criterion sort in a Turkish sample $(r=.86)$.

The second profile found in the sample seems to represent mothers' nonsynchronous behaviours underlying lack of harmony with their child. Mothers having high positive loading on this factor are mostly showing interfering behaviours and deciding content and pace of interactions without considering infant's needs and cues. This finding is consistent with Bailey and colleagues' $(1999,2007)$ previous findings with a high-risk sample, adolescent mothers in age ranged from 16-19. The sample of the current study is also a high-risk, economically disadvantaged sample. The difference in the current study is that the proportion of mothers with high loadings on this factor was relatively higher (about 20\%) than it was in Bailey's studies (about 10\%). In future studies, why and how those risk factors (being young or economically disadvantaged) are related to nonsynchronous maternal behaviours might be investigated. Also, whether other risk factors (e.g. mothers' adjustment problems, child difficult temperament) are related to nonsynchronous maternal behaviours might be examined.

The other study conducted in Turkey (Aran et al., in press) using q-methodology revealed a similar first profile and a second profile that was more relevant to indifferent maternal behaviour. That study; however, had methodological differences. They conducted on sight coding right after observation rather than video recording like in our study. They also had a more restricted age range for infants and a younger mean age. Finally, it was conducted with a low-risk sample. All these accounts might potentially contribute to the differences in the content of the second maternal profiles across the two studies. For both studies, replications can answer those questions.

As shown in the meta-analytic study conducted by Cyr, Euser, Bakermans-Kranenburg, and van IJzendoorn (2010), children living in high-risk conditions are more likely to have insecure or disorganised attachment styles regardless of experiencing maltreatment. Also, previous studies (e.g. Selçuk et al., 2010; Simona et al., 2014) have shown low SES as a risk factor for maternal insensitivity. Therefore, understanding maternal profiles in such samples with low SES has become essential in the attachment literature. To our knowledge, there has been no study examining maternal caregiving profiles deeply with observations via the MBQS method specifically with samples from low SES backgrounds. Hence, the current study as a first study examining those profiles in such a sample has provided a useful resource not only for attachment literature but also for attachmentbased, maternal sensitivity focused intervention programmes. 
Previous cross-cultural studies have demonstrated that cultural differences may reflect culturally specific perceptions and preferences of maternal sensitivity. For example, Ziehm, Trommsdorf, Heikamp, and Park (2013) found that German mothers, compared to South Korean mothers, were more likely to prefer reactive sensitivity (waiting for children's direct signals to respond) rather than proactive sensitivity (anticipating child's needs). Similar Western-Eastern cultural differences in reactive and proactive preferences were found between German and Japanese mothers (Trommsdorff \& Friedlmeier, 2010), and between American and Japanese mothers (Rothbaum et al., 2006). Even though there has been no study directly investigating proactive or reactive preferences among Turkish mothers, there is a general opinion suggesting that in Turkey, where children's relatedness and interdependence are highly valued, maternal caregiving is mostly shaped by proactive caregiving behaviours (Sümer \& Kağıtçıbaşı, 2010). Hence, it might be speculated that nonsynchronous behaviours found as a second caregiving profile in this study might be related to possible proactive preferences, which seems to be characterised by intrusive caregiving in the cultural context of Turkey. Related to this, the prevalence of nonsynchronous maternal behaviours in Turkey should be considered in designing parenting intervention programmes, and suitable alternative steps to parents (e.g. 'let the child lead', 'watch wait wonder') can be recommended.

As Posada et al. (2016) suggested, sensitive caregiving behaviours might vary depending on the culture though ideal sensitivity is described similarly across cultures (Mesman et al., 2016). Still, comparing caregiving behaviours with 'ideal' criteria described by mostly Western studies would be misleading in understanding cultural variations. Therefore, in the current study, naturalistic observations were evaluated via q-factor analyses giving more detailed behavioural patterns and the possibility to compare the patterns emerging within the culture.

Our findings should be interpreted considering the potential limitations of the study. Video recording of interactions could influence reflecting natural maternal behaviours. Using a convenient sample, having relatively low recruitment rate, and lacking sample size calculation before collecting data are the other limitations of the study. In future studies, natural observations without video recordings and more representative and larger samples would be helpful to enhance the external validity of the findings. Moreover, in future studies, not only the descriptions of such profiles but also perceptions of children for these profiles should be examined to understand a broader picture of mother-child interactions. In cultures where parents are expected to respond before children give a sign, children might perceive parental control less negatively compared to other cultures (Sümer \& Kağıtçıbaşı, 2010). Considering such cultural differences, how children perceive nonsynchronous behaviours, and how this can be applied to intervention programmes should be investigated in the future.

\section{Disclosure statement}

No potential conflict of interest was reported by the authors.

\section{Funding}

This work was supported by the Scientific and Technological Research Council of Turkey [113K542]. 


\section{ORCID}

Özlü Aran (D) http://orcid.org/0000-0002-5864-9828

Selin Salman Engin (D) http://orcid.org/0000-0002-2972-9204

\section{References}

Aber, L., Jones, S., \& Cohen, J. (2000). The impact of poverty on the mental health and the development of very young children. In C. H. Zeanah (Ed.), Handbook of infant mental health (pp. 113-128). New York: Guildford Press.

Ainsworth, M. D. S., Bell, S. M., \& Stayton, D. J. (1971). Individual differences in strange situation behavior of one-year-olds. In H. R. Schaffer (Ed.), The origins of human social relations (pp. 17-58). London: Academic Press.

Ainsworth, M. D. S., Bell, S. M., \& Stayton, D. J. (1974). Infant-mother attachment and social development. In M. P. Richards (Ed.), The introduction of the child into a social world (pp. 99-135). London: Cambridge University Press.

Ainsworth, M. D. S., Blehar, M. C., Waters, E., \& Wall, S. N. (1978). Patterns of attachment: A psychological study of the strange situation. Hillsdale, NJ: Erlbaum.

Aran, Ö., Iplikci, A. B., Selçuk, E., \& Günaydın, G. (in press). Türkiye'de anne bakımverme davranışlarındaki çeşitliliğin tanımlanması ve annenin duygusal tepkiselliğiyle ilişkisi: Bir doğal gözlem çalışması [Associations of depression and anxiety symptoms with naturally occurring variation in maternal caregiving observed in-home setting]. Turkish Journal of Psychology, 86. doi: 10.31828/tpd1300443320190729m000023

Aviezer, O., Sagi-Schwartz, A., \& Koren-Karie, N. (2003). Ecological constraints on the formation of infant-mother attachment relations: When maternal sensitivity becomes ineffective. Infant Behavior and Development, 26, 285-299.

Bailey, H. N., Moran, G., Pederson, D. R., \& Bento, S. (2007). Understanding the transmission of attachment using variable- and relationship-centered approaches. Development and Psychopathology, 19, 313-343.

Bailey, H. N., Waters, C. A., Pederson, D. R., \& Moran, G. (1999). Ainsworth revisited: An empirical analysis of interactive behavior in the home. Attachment \& Human Development, 1, 191-216.

Bornstein, M. H., \& Tamis-LeMonda, C. S. (1989). Maternal responsiveness and cognitive development in children. In M. H. Bornstein (Ed.), Maternal responsiveness: Characteristics and consequences (pp. 49-61). San Francisco: Jossey-Bass.

Bowlby, J. (1983). Attachment: Attachment and loss. New York: Basic Books.

Bradley, R. H., \& Corwyn, R. F. (2008). Infant temperament, parenting, and externalizing behavior in first grade: A test of the differential susceptibility hypothesis. Journal of Child Psychology and Psychiatry, and Allied Disciplines, 49, 124-131.

Broesch, T., Rochat, P., Olah, K., Broesch, J., \& Henrich, J. (2016). Similarities and differences in maternal responsiveness in three societies: Evidence from Fiji, Kenya, and the United States. Child Development, 87, 700-711.

Cattell, R. B. (1966). The scree test for the number of factors. Multivariate Behavioral Research, 1, 629-637.

Choe, D. E., Olson, S. L., \& Sameroff, A. J. (2013). Effects of early maternal distress and parenting on the development of children's self-regulation and externalizing behavior. Development and Psychopathology, 25, 437-445.

Cyr, C., Euser, E. M., Bakermans-Kranenburg, M. J., \& van IJzendoorn, M. H. (2010). Attachment security and disorganization in maltreat-ing and high-risk families: A series of meta-analyses. Development \& Psychopathology, 22(1), 87-108.

Evans, J., Heron, J., Lewis, G., Araya, R., \& Wolke, D. F. H. (2005). Negative self-schemas and the onset of depression in women: Longitudinal study. British Journal of Psychiatry, 186, 302-307.

Fiese, B. H., Rhodes, H. G., \& Beardslee, W. R. (2013). Rapid changes in American family life: Consequences for child health and pediatric practice. Pediatrics, 132, 552-559. 
Heron, J., O'Connor, T. G., Evans, J., Golding, J., Glover, V. \& The ALSPAC Study Team. (2004, May). The course of anxiety and depression through pregnancy and the postpartum in a community sample. Journal of Affective Disorders, 80, 65-73.

İnalcık, H. (1998). Turkey between Europe and the Middle East. Journal of International Affairs, 3, 1-7. Kağıtçıbaşı, Ç. (2005). Autonomy and relatedness in cultural context: Implications for self and family. Journal of Cross-Cultural Psychology, 36, 403-422.

Kağıtçıbaşı, Ç., \& Ataca, B. (2005). Value of children and family change: A three-decade portrait from Turkey. Applied Psychology, 54, 317-337.

Landry, S. H., Smith, K. E., \& Swank, P. R. (2006). Responsive parenting: Establishing early foundations for social, communication, and independent problem-solving skills. Developmental Psychology, $42,627-642$.

Lemelin, J., Boivin, M., Forget-Dubois, N., Dionne, G., Seguin, J. R., Brendgen, M., \& P'erusse, D. (2007). The genetic-environmental etiology of cognitive school readiness and later academic achievement in early childhood. Child Development, 78, 1855-1869.

McLoyd, V. C., \& Wilson, L. (1991). The strain of living poor: Parenting, social support and child mental health. In A. Huston (Ed.), Children in poverty: Child development and public policy (pp. 105-135). New York: Cambridge University.

Mesman, J., van ljzendoorn, M., Behrens, K., Carbonell, O. A., Cárcamo, R., Cohen-Paraira, I., \& Zreik, G. (2016). Is the ideal mother a sensitive mother? Beliefs about early childhood parenting in mothers across the globe. International Journal of Behavioral Development, 40, 385-397.

Pederson, D. R., Moran, G., Sitko, C., Campbell, K., Ghesquire, K., \& Acton, H. (1990). Maternal sensitivity and the security of infant-mother attachment: A q-sort study. Child Development, 61, 1974-1983.

Pederson, D. R., \& Moran, G. A. (1995). Categorical description of attachment relationships in the home and its relation to q-sort measures of infant-mother interaction. Monographs of the Society for Research in Child Development, 60, 111-132.

Posada, G., Carbonell, O. A., Alzate, G., \& Plata, S. J. (2004). Through Colombian lenses: Ethnographic and conventional analyses of maternal care and their associations with secure base behavior. Developmental Psychology, 40, 508-518.

Posada, G., Trumbell, J., Noblega, M., Plata, S., Pena, P., Carbonell, O. A., \& Lu, T. (2016). Maternal sensitivity and child secure base use in early childhood: Studies in different cultural contexts. Child Development, 87, 297-311.

Rogoff, B. (2003). The cultural nature of human development. New York, NY: Oxford University Press.

Rothbaum, F., Nagaoka, R., \& Ponte, I. C. (2006). Caregiver sensitivity in cultural context: Japanese and U.S. teachers' beliefs about anticipating and responding to children's needs. Journal of Research in Childhood Education, 21, 23-40.

Rothbaum, F., Weisz, J., Pott, M., Miyake, K., \& Morelli, G. (2000). Attachment and culture: Security in the United States and Japan. American Psychologist, 55, 1093-1104.

Roubinov, D. S., \& Boyce, W. T. (2017). Parenting and SES: Relative values or enduring principles? Current Opinion in Psychology, 15, 162-167.

Sameroff, A. J. (1998). Environmental risk factors in infancy. Pediatrics, 102, 1287-1292.

Sameroff, A. J. (2000). Developmental systems and psychopathology. Development and Psychopathology, 12, 297-312.

Selçuk, E., Günaydın, G., Sümer, N., Harma, M., Salman, S., Hazan, C., .. Öztürk, A. (2010). Selfreported romantic attachment style predicts everyday maternal caregiving behavior at home. Journal of Research in Personality, 44, 544-549.

Seow, W. K. (2012). Environmental, maternal, and child factors which contribute to early childhood caries: A unifying conceptual model. International Journal of Paediatric Dentistry, 22, 157-168.

Shin, H., Park, Y., \& Kim, M. (2006). Predictors of maternal sensitivity during the early postpartum period. Journal of Advanced Nursing, 55, 425-434.

Simona, D. F., Alessandra, E., Laura, M., Rigo, P., Pruner, S., \& Venuti, P. (2014). Predictors of mother-child interaction quality and child attachment security in at-risk families. Frontiers in Psychology, 5, 966. 
Sümer, N., \& Kağıtçıbaşı, Ç. (2010). Culturally relevant parenting predictors of attachment security: Perspectives from Turkey. In P. Erdman \& N. Kok-Mun (Eds.), Attachment: Expanding the cultural connections (pp. 157-179). New York: Routledge Press.

Sümer, N., Sayıl, M., \& Kazak-Berument, S. (2016). Anne Duyarlığı ve çocuklarda bağlanma: Anne Duyarlığı Sınıflama Seti ve Bağlanma Davranışı Sınıflama Seti. İstanbul: Koç Press.

Tamis-LeMonda, C. S., Bornstein, M. H., \& Baumwell, L. (2001). Maternal responsiveness and children's achievement of language milestones. Child Development, 72, 748-767.

Tarabulsy, G. M., Bernier, A., Provost, M. A., Maranda, J., Larose, S., Moss, E., ... Tessier, R. (2005). Another look inside the gap: Ecological contributions to the transmission of attachment in a sample of adolescent mother-infant dyads. Developmental Psychology, 41, 212-224.

Trommsdorff, G., \& Friedlmeier, W. (2010). Preschool girls'distress and mothers' sensitivity in Japan and Germany. European Journal of Developmental Psychology, 7(3), 350-370.

TURKSTAT. (2015). Income and living conditions survey. Retrieved from http://www.turkstat.gov.tr/ PreTablo.do?alt_id=1013

TURKSTAT. (2017). Income and living conditions survey. Retrieved from http://www.turkstat.gov.tr/ PreTablo.do?alt_id=1013

van ljzendoorn, M. H., \& Sagi, A. (1999). Cross-cultural patterns of attachment. In J. Cassidy \& P. R. Shaver (Eds.), Handbook of attachment (pp. 713-734). New York, NY: Guilford Press.

van ljzendoorn, M. H., \& Sagi-Schwartz, A. (2008). Cross-cultural patterns of attachment: Universal and contextual dimensions. In J. Cassidy \& P. R. Shaver (Eds.), Handbook of attachment: Theory, research, and clinical applications (pp. 880-905). New York, NY: The Guilford Press.

Zabala, A. (2014). qmethod: A package to explore human perspectives using $Q$ methodology. The $R$ Journal, 6, 163-173. Retrieved from http://journal.r-project.org/archive/2014-2/zabala.pdf

Ziehm, J., Trommsdorf, G., Heikamp, T., \& Park, S. (2013). German and Korean mothers' sensitivity and related parenting beliefs. Frontiers in Psychology, 4, 1-9. 